\title{
Composição físico-química de leites em diferentes fases de lactação
}

\author{
Physico-chemical composition of milk at different stages of lactation
}

\author{
Emanuel Neto Alves de Oliveira ${ }^{[a]}$, Dyego da Costa Santos ${ }^{[a]}$, Arali da Silva Oliveira ${ }^{[b]}$, \\ Francinalva Cordeiro de Sousa ${ }^{[\mathrm{c}]}$
}

[a] Tecnólogo em alimentos, Mestrando em Engenharia Agrícola pela Universidade Federal de Campina Grande (UFCG), Campina Grande, PB - Brasil, e-mail: emanuelnetoliveira@ig.com.br; dyego.csantos@gmail.com

[b] Química industrial e Licenciada em Química, Mestranda em Engenharia Agrícola pela Universidade Federal de Campina Grande (UFCG), Campina Grande, PB - Brasil, e-mail: aralisilva@hotmail.com

[c] Tecnóloga em alimentos, Especialista em Ensino da Química pela Universidade Regional do Cariri (URCA), Crato, CE - Brasil, e-mail: francis_nalva@yahoo.com.br

\section{Resumo}

Esta pesquisa teve como objetivo avaliar a variabilidade dos componentes físico-químicos de amostras de leite produzidas por vacas Nelore-Holandesa em diferentes fases de lactação. Foram coletadas cinco amostras seguindo-se o cronograma: 15 dias, 1 mês, 6 meses, 12 meses e 18 meses de lactação. As amostras foram submetidas às análises físico-químicas quanto aos teores de gordura, proteínas, extrato seco desengordurado, lactose, densidade a $15^{\circ} \mathrm{C}$, índice crioscópico e $\mathrm{pH}$, utilizando-se o aparelho Ekomilk. Os resultados foram submetidos à análise de variância (ANOVA) e a comparação de médias foi feita pelo teste de Tukey ao nível de 5\% de probabilidade. Os teores de gordura variaram de 2,39\% a 7,81\% ao longo do período de lactação; a maior porcentagem de proteína obtida foi de 3,91\% (12 meses de lactação); as maiores porcentagens de extrato seco desengordurado $(11,1 \%)$ e lactose $(6,3 \%)$ foram determinadas nas amostras de 12 meses e de 18 meses, respectivamente. Observou-se que houve aumento gradativo nos valores de pH de 6,93 (15 dias de lactação) a 7,11 (12 meses de lactação). Todas as amostras apresentaramse em desacordo quanto ao índice crioscópico. Em contrapartida, os resultados para densidade estavam de acordo com o estabelecido pela legislação vigente. O teor de gordura, o extrato seco desengordurado e a lactose foram as características estudadas que mais variaram no decorrer do período de lactação. $\mathrm{O}$ teor de proteína apresentou menor variação no decorrer do período de lactação, assim como o pH.

Palavras-chave: Constituintes físico-químicos. Fases de lactação. Vacas mestiças Nelore-Holandesa. 


\begin{abstract}
The research aimed to evaluate the variability of physicochemical components of samples of milk produced by cows Nellore-Holstein at different stages of lactation. Five samples were collected following the schedule: 15 days, 1 month, 6 months, 12 months and 18 months of lactation. The samples were subjected to physical-chemical analysis for the determination of fat, protein, nonfat solids, lactose, density at $15{ }^{\circ} \mathrm{C}$, cryoscopic index and $p H$ using the Ekomilk apparatus. The results were subjected to analysis of variance ( ANOVA) and comparison of means by Tukey test at $5 \%$ of probability. Fat content ranged from $2.39 \%$ the $7.81 \%$ throughout the lactation period, the highest percentage of protein was 3.91\% (12 months of lactation), the highest percentage of non fat solids $(11.1 \%)$ and lactose $(6.3 \%)$ were obtained in samples from 12 months and 18 months of lactation, respectively. It was observed a gradual increase in $\mathrm{pH}$ values from 6.93 (15 days of lactation) to 7.11 (12 months of lactation). All samples were in disagreement as to cryoscopy index. In counterpart, the results for density were in accordance with current law. Among the milk components, to the fat, the nonfat solids and the lactose showed greater variation during the lactation period than other components. The protein content showed less variation during the lactation period, as well as $p H$.
\end{abstract}

Keywords: Physical-chemical constituents. Stages of lactation. Crossbred cows Nellore-Holstein.

\title{
Introdução
}

Segundo o Regulamento de Inspeção Industrial e Sanitária de Produtos de Origem Animal do Ministério da Agricultura e Pecuária de Abastecimento (RIISPOA), entende-se por leite o produto oriundo da ordenha completa e ininterrupta, em condições de higiene, de vacas sadias, bem alimentadas e descansadas (BRASIL, 1962). O leite de outros animais, a não ser o leite obtido de vacas, deve ser denominado segundo a espécie de que proceda. É um alimento de grande importância na alimentação humana, graças ao seu elevado valor nutritivo. Por causa do seu valor nutricional, o leite torna-se também um excelente meio para o crescimento de vários grupos de micro-organismos desejáveis e indesejáveis (SOUZA et al., 1995).

O leite de vaca possui em média 3,5\% de proteínas, 3,8\% de gordura, 5,0\% de lactose, $0,7 \%$ de minerais (cinzas) e $87 \%$ de água. Esses valores médios podem apresentar desvios, uma vez que a variação da composição do leite é muito grande e em todos os componentes a fração que mais varia é a constituída pela gordura. Os sólidos não gordurosos, que compreendem todos os elementos do leite menos a água e a gordura, representam, em média, 8,9\% do total no leite (BEHMER, 1999; RAPACCI, 2000).

De acordo com o Regulamento Técnico de Identidade e Qualidade do Leite Cru Refrigerado contido na Instrução Normativa n. 51 (BRASIL, 2002), o leite cru refrigerado deverá atender os requisitos físicoquímicos de gordura (mínimo de $3 \mathrm{~g} / 100 \mathrm{~g}$ ), densidade relativa a $15^{\circ} \mathrm{C}(1,028$ a 1,034 g / $100 \mathrm{~mL}$ ), acidez titulável (0,14 a 0,18 g de ácido láctico / $100 \mathrm{~mL}$ ), extrato seco desengordurado (mínimo de 8,4 g / $100 \mathrm{~g}$ ), índice crioscópico (máximo de $-0,530^{\circ} \mathrm{H}$ ) e proteína (mínimo de 2,9 g / $100 \mathrm{~g}$ ).

A produção e as características físico-químicas do leite podem ser alteradas facilmente pela manipulação; ação de micro-organismos; por fatores nutricionais (SANTOS; XAVIER; PASSOS, 1981); fraudes do produto (PADILHA; FERNANDES, 1999); por fatores ambientais, onde se destacam, principalmente, fases de lactação, intervalo entre as ordenhas (BEHMER, 1999; RAPACCI, 2000), a alimentação (RESTLE; PACHECO; MOLETTA, 2003); e por fatores genéticos (ALBUQUERQUE et al., 1993).

A fase de lactação representa importante fator de variação nas características de composição do leite. Pesquisas indicam que os valores de proteína, lipídios e lactose aumentam no decorrer da lactação (AGANGA; AMARTEIFIO; NKILE, 2002; PRASAD; SENGAR, 2002).

Estudos desenvolvidos no Departamento de Clínica Médica e no Centro de Pesquisa e Diagnóstico de Enfermidades de Ruminantes da Faculdade de Medicina Veterinária da Universidade de São Paulo permitem afirmar que durante o período de lactação plena (entre 7 e 305 dias de lactação) há variação dos 
componentes nutricionais do leite, entre eles destacam-se os valores de proteína, que variam entre 3,28 e 3,77 g/dL; de gordura, entre 1,74 e 2,98 g/dL, e de sólidos totais entre 10,84 e 11,82 g/dL (BIRGEL Jr., 2006; SANT'ANA, 2004).

A idade da vaca é outro fator que influencia a produção de leite, constituindo-se em importante fonte de variação. De acordo com Cobuci et al. (2000), as variações que ocorrem com o avanço da idade da vaca são, principalmente, causadas por fatores fisiológicos e proporcionam desempenhos máximos com a maturidade do animal.

Bramley e Mckinnon (1990), Cerqueira et al. (1994) e Soler, de Paz e Nuñez (1995) relatam que fatores como deficiências no manejo e higiene de ordenha, índices elevados de mastite, manutenção e desinfecção inadequadas dos equipamentos, refrigeração ineficiente ou inexistente e mão de obra desqualificada contribuem para a má qualidade do leite cru.

Esta pesquisa teve como objetivo avaliar a variabilidade dos componentes físico-químicos de amostras de leite produzidas por vacas Nelore-Holandesa em diferentes fases de lactação.

\section{Material e métodos}

\section{Coleta de amostras}

O material para a realização da pesquisa foi constituído de cinco amostras de leite cru de vacas mestiças Nelore-Holandesa em diferentes períodos de lactação. Utilizou-se o leite de cinco animais sadios, seguindo-se as normas de obtenção recomendadas pelas Boas Práticas de Fabricação (BPF). A pesquisa foi realizada no primeiro semestre de 2009 , e as amostras utilizadas para pesquisa foram provenientes de uma fazenda de gado leiteiro localizada no município de Mauriti, CE. O município de Mauriti está localizado na região do Cariri Cearense, a $491 \mathrm{~km}$ de Fortaleza pela BR-116, fazendo divisa com as cidades de Barro, Milagres e Brejo Santo e com os Estados da Paraíba e Pernambuco.

As amostras foram coletadas seguindo-se o cronograma: 15 dias, 1 mês, 6 meses, 12 meses e 18 meses de lactação. Vale salientar que os animais utilizados no estudo possuíam semelhanças de idade $(7$ e 8 anos) e mesmo número de parições (duas parições); a alimentação foi exclusivamente em pasto natural, não sendo fornecido nenhum tipo de alimentação complementar. Foram utilizados cinco animais e cada animal correspondeu a uma fase de lactação, destes foi coletada uma amostra para subsequentes análises.

As amostras foram coletadas em frascos de vidro esterilizados e armazenadas imediatamente sob refrigeração na temperatura de $4{ }^{\circ} \mathrm{C}$, evitando-se o desenvolvimento de micro-organismos indesejáveis.

\section{Análises físico-químicas}

As amostras foram submetidas às análises físico-químicas quanto aos teores de gordura, proteínas, extrato seco desengordurado, lactose, densidade a $15^{\circ} \mathrm{C}$, índice crioscópico e $\mathrm{pH}$ com quatro repetições para cada amostra analisada. As análises foram realizadas no Laboratório de Química de Alimentos da Faculdade de Tecnologia Centec, Cariri, por método rápido, utilizando o aparelho Ekomilk, do fabricante Cap-Lab, conforme recomendação do fabricante.

\section{Análise estatística}

O delineamento experimental foi o de blocos inteiramente casualizados com cinco tratamentos e quatro repetições, utilizando-se o software Assistat (SILVA; AZEVEDO, 2009). Os dados foram submetidos à análise de variância (ANOVA) e a comparação de médias foi feita pelo teste de Tukey ao nível de 5\% de probabilidade. 


\section{Resultados e discussão}

Os valores dos componentes físico-químicos do leite de vacas mestiças Nelore-Holandesa em diferentes períodos de lactação estão apresentados na Tabela 1.

Tabela 1 - Análises físico-químicas de amostras de leite coletadas em diferentes períodos de lactação

\begin{tabular}{|c|c|c|c|c|c|c|c|}
\hline $\begin{array}{l}\text { Período de } \\
\text { lactação }\end{array}$ & $\begin{array}{c}\text { Gordura } \\
(\%)\end{array}$ & $\begin{array}{c}\text { Proteína } \\
(\%)\end{array}$ & $\begin{array}{c}\text { Extrato seco } \\
\text { desengordurado } \\
(\%)\end{array}$ & $\begin{array}{c}\text { Lactose } \\
(\%)\end{array}$ & $\begin{array}{l}\text { Densidade } \\
(\mathrm{g} / \mathrm{mL})\end{array}$ & $\begin{array}{c}\text { Índice } \\
\text { crioscópico } \\
\left({ }^{\circ} \mathrm{H}\right)\end{array}$ & $\mathrm{pH}$ \\
\hline 15 dias & $3,05^{\mathrm{e}}$ & $2,63^{d}$ & $7,47^{d}$ & $4,53^{\mathrm{cd}}$ & $1,029^{\mathrm{c}}$ & $-0,537^{\mathrm{c}}$ & $6,93^{\mathrm{b}}$ \\
\hline 1 mês & $4,45^{d}$ & $2,60^{d}$ & $7,58^{d}$ & $4,42^{\mathrm{d}}$ & $1,026^{\mathrm{d}}$ & $-0,543^{\mathrm{b}}$ & $7,03 \mathrm{ab}$ \\
\hline 6 meses & $6,74 \mathrm{~b}^{\mathrm{c}}$ & $2,79^{\mathrm{c}}$ & $8,04^{\mathrm{c}}$ & $4,56^{\mathrm{c}}$ & $1,025^{\mathrm{d}}$ & $-0,548^{a}$ & $7,05^{a}$ \\
\hline 12 meses & $7,13^{\mathrm{b}}$ & $3,91^{\mathrm{a}}$ & $10,40^{\mathrm{b}}$ & $6,30^{a}$ & $1,037^{a}$ & $-0,545^{\mathrm{b}}$ & $7,11^{a}$ \\
\hline 18 meses & $7,81^{\text {a }}$ & $3,69^{\mathrm{b}}$ & $11,10^{a}$ & $5,96^{\mathrm{b}}$ & $1,034^{b}$ & $-0,545^{\mathrm{b}}$ & $7,10^{a}$ \\
\hline Média geral & 5,84 & 3,12 & 8,92 & 5,15 & 1,030 & $-0,544$ & 7,04 \\
\hline Fcal & $2354,1680^{* *}$ & $560,8076^{* *}$ & $2145,6798^{* *}$ & $1153,5748^{* *}$ & $80,1000^{* *}$ & $50,4000^{* *}$ & $7,4712^{* *}$ \\
\hline $\mathrm{CV} \%$ & 1,41576 & 1,69530 & 0,82502 & 1,02770 & 0,11209 & 0,21242 & 0,74762 \\
\hline
\end{tabular}

${ }^{1}$ Legenda: $\mathrm{ns}=$ não significativo; $*$ significativo a $5 \%$; $\mathrm{e}^{* *}=$ significativo a $1 \%$ de probabilidade pelo teste $\mathrm{F}$.

Médias seguidas da mesma letra, na coluna, não diferem estaticamente a $5 \%$ de probabilidade pelo teste de Tukey.

Fonte: Dados da pesquisa.

Observou-se que os teores de gordura variaram de 2,39\% a 7,81\%. Quanto maior o período da lactação maiores são os teores de gordura encontrados no leite. Os valores encontrados para gordura, a partir de um mês de lactação, foram superiores aos citados por Venturini, Sarcinelli e Silva (2007), que pesquisando as características de amostras de leite cru obtiveram valor médio de 3,5\%. Todas as amostras analisadas estavam de acordo com a Instrução Normativa n. 51 (BRASIL, 2002), que estabelece teor mínimo de 3\% de gordura para leite cru refrigerado.

Para a determinação de proteínas, a maior porcentagem obtida foi de 3,91\% na amostra coletada aos 12 meses de lactação, e a menor porcentagem foi de 2,6\% na amostra coletada após 1 mês de lactação, cujo valor se mostrou estatisticamente igual ao da amostra coletada aos 15 dias de lactação. Apenas as amostras coletadas com 12 e 18 meses de lactação encontraram-se dentro dos padrões estabelecidos pela legislação brasileira de no mínimo 2,9\% (BRASIL, 2002). Chenette e Frahm (1981) não verificaram diferença significativa para o teor de proteína do leite de vacas provenientes de diferentes cruzamentos (bi-cross), porém, vacas mestiças Jersey-Hereford apresentaram maior porcentagem de gordura no leite (5,12\%), enquanto vacas mestiças Pardo-Suíço Angus apresentaram o teor mais baixo (4,65\%). Mais recentemente, Cruz, Alencar e Túlio (1997) não verificaram diferença para teor de proteína no leite de vacas Nelore e Canchim (3,73\% e 3,56\%, respectivamente); entretanto, vacas Nelore apresentaram maiores teores de gordura e extrato seco total no leite $(5,53 \%$ e 14,58\%, respectivamente) do que vacas da raça Canchim (4,74\% e 13,58\%, respectivamente).

Percebe-se que há maior aumento do teor de gordura $(3,05 \%$ a $7,81 \%)$ em relação ao de proteína (2,63\% a 3,69\%) no leite com o decorrer do tempo de lactação do animal (Gráfico 1).

As maiores porcentagens de extrato seco desengordurado $(11,1 \%)$ e lactose $(6,3 \%)$ foram obtidas nas amostras coletadas aos 12 e 18 meses de lactação, respectivamente. Esses valores foram superiores aos estudados por Cerdótes et al. (2004), que obtiveram valores de extrato seco desengordurado entre 8,55\% e $8,75 \%$, e os de Gonzalez et al. (2004), que obtiveram valor médio de 4,44\% para lactose. 


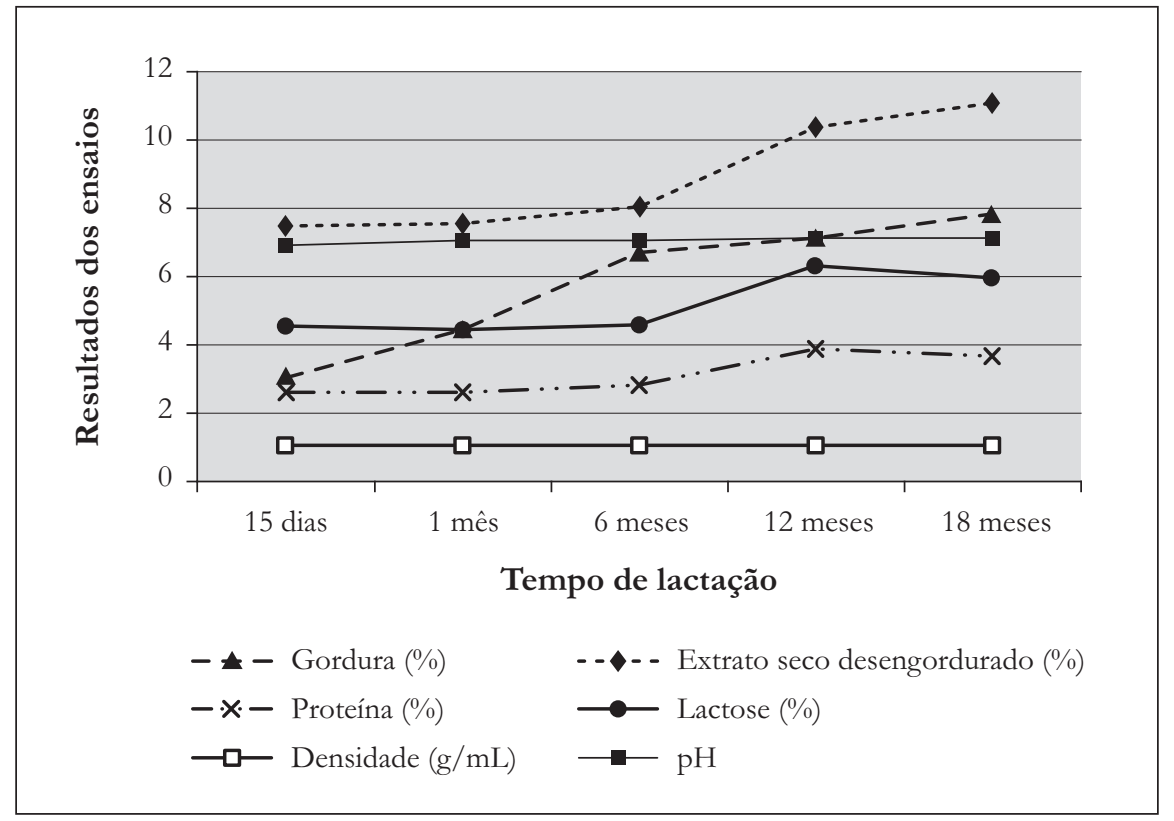

Gráfico 1 - Teores em porcentagem de gordura, proteína, densidade, extrato seco desengordurado, lactose e valores de $\mathrm{pH}$ em amostras de leite de diferentes fases de lactação

Fonte: Dados da pesquisa.

Observa-se na Tabela 1 que houve aumento gradativo nos valores de $\mathrm{pH}$ de 6,93 (15 dias de lactação) a 7,11 (12 meses de lactação). O pH da amostra de leite aos 15 dias de lactação diferiu estatisticamente das amostras coletadas com 6,12 e 18 meses de lactação. Os resultados obtidos foram semelhantes aos citados por Raimondo et al. (2009), que, pesquisando as características físico-químicas de leites em diferentes dias de lactação, obtiveram aumento nos valores de pH de 6,37 (12 horas de lactação) a 6,71 (30 dias de lactação). Segundo Venturini et al. (2007), o pH do leite recém-ordenhado de uma vaca sadia pode variar entre 6,4 a 6,8 e também pode ser um indicador da qualidade sanitária e da estabilidade térmica do leite. Nos casos graves de mastite, o pH pode chegar a 7,5 e, na presença de colostro, pode cair a 6,0.

$\mathrm{Na}$ determinação do índice crioscópico (Gráfico 2), todas as amostras analisadas encontraram-se fora dos padrões estabelecidos pela Instrução Normativa n. 51 (BRASIL, 2002), que estabelece índice crioscópico máximo de $-0,530^{\circ} \mathrm{H}$ para leite cru refrigerado. Observou-se que houve variação no índice crioscópico de $-0,537^{\circ} \mathrm{H}$ (15 dias de lactação) a $-0,548^{\circ} \mathrm{H}$ (6 meses de lactação). Os resultados obtidos são semelhantes aos citados por Fagan et al. (2008), que obtiveram variações de $-0,539{ }^{\circ} \mathrm{H}\left(0\right.$ a 90 dias de lactação) a $-0,545^{\circ} \mathrm{H}$ (270 dias de lactação).

Os resultados do índice crioscópico das amostras de leite de 1, 12 e 18 meses de lactação não diferiram estatisticamente pelo teste de Tukey ao nível de $1 \%$ de probabilidade.

Para a análise de densidade a $15^{\circ} \mathrm{C}$ foi obtida uma variação de $1,025 \mathrm{~g} / \mathrm{mL}$ (6 meses de lactação) e $1,037 \mathrm{~g} / \mathrm{mL}$ (12 meses de lactação). Os resultados encontraram-se dentro dos padrões estabelecidos pela legislação brasileira que estabelece valores de 1,028 a $1,034 \mathrm{~g} / \mathrm{mL}$ a $15{ }^{\circ} \mathrm{C}$ (BRASIL, 2002). O resultado para densidade obtido em um mês de lactação não diferiu estatisticamente da amostra coletada aos seis meses de lactação pelo teste estatístico aplicado.

A densidade do leite é uma relação entre seu peso e volume e é normalmente medida a $15{ }^{\circ} \mathrm{C}$ ou corrigida para essa temperatura. A densidade do leite de vaca é, em média, 1,032 g/mL, podendo variar entre 1,023 e 1,040 g/mL. Mediante essa determinação é possível avaliar a relação entre os sólidos e o solvente no leite, sendo utilizada juntamente com o teste de gordura para determinar o teor de sólidos do leite. 


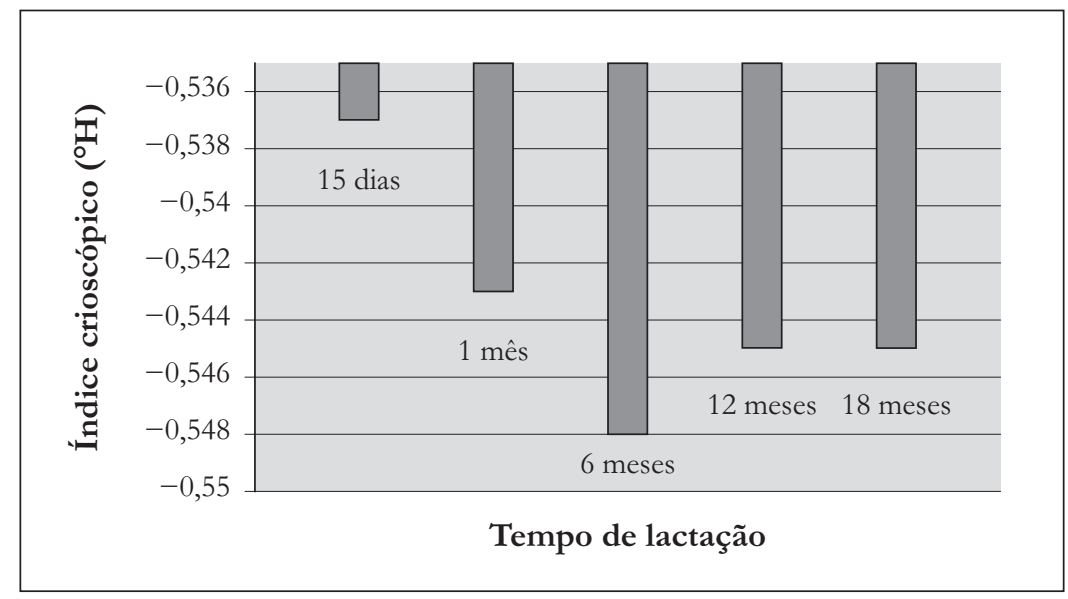

Gráfico 2 - Valores do índice crioscópico em amostras de leite de diferentes fases de lactação

Fonte: Dados da pesquisa.

\section{Conclusão}

Entre os componentes do leite, o teor de gordura, o extrato seco desengordurado e a lactose foram as variáveis estudadas que mais oscilaram no decorrer do período de lactação. De maneira geral, a porcentagem de gordura do leite foi o parâmetro que mais aumentou gradualmente ao longo da lactação. O teor de proteína apresentou menor variação no decorrer do período de lactação, assim como o pH.

\section{Referências}

AGANGA, A. A.; AMARTEIFIO, J. O.; NKILE, N. Effect of stage of lactation on nutrient composition of Tswana sheep and goat's milk. Journal of Composition and Analysis, v. 15, n. 5, p. 533-543, 2002.

ALBUQUERQUE, L. G. et al. Produção de leite e desempenho do bezerro na fase de aleitamento em três raças bovinas de corte. Revista da Sociedade Brasileira de Zootecnia, v. 22, n. 5, p. 745-754, 1993.

BEHMER, M. L. A. Tecnologia do leite: queijo, manteiga, caseína, iogurte, sorvetes e instalações: produção, industrialização, análise. 13. ed. São Paulo: Nobel, 1999.

BIRGEL Jr., E. H. Características físico-químicas, celulares e microbiológicas do leite de bovinos das raças Holandesa, Gir e Girolando criados no Estado de São Paulo. 2006. 335 f. Tese (Livre Docência) - Faculdade de Medicina Veterinária e Zootecnia, Universidade de São Paulo, São Paulo, 2006.

BRAMLEY, A. J.; MCKINNON, C. H. The microbiology of raw milk. In: ROBINSON, R. K. Dairy microbiology: the microbiology of milk. In: ROBINSON, R. K. Dairy microbiology: the microbiology of milk. 2nd ed. London: Elsevier Science, 1990. p. 163-207.

BRASIL. Ministério da Agricultura, Pecuária e Abastecimento. Instrução Normativa n. 51, de 20 de setembro de 2002. Aprova os regulamentos técnicos de produção, identidade e qualidade do leite. Diário Oficial [da] República Federativa do Brasil, Brasília, DF, p. 13, Seção 1, 21 set. 2002. Disponível em: <http://extranet.agricultura.gov.br/ sislegis-consulta/consultarLegislacao.do?operacao=visualizar\&id=8932> . Acesso em: 10 set. 2010.

BRASIL. Decreto 30.691 de 29 de março de 1952 alterado pelo Decreto 1.255 de 25 de junho de 1962. Regulamenta Inspeção Industrial Sanitária de Produtos de Origem Animal (Riispoa). Diário Oficial [da] República Federativa do Brasil, Brasília, DF,1962. Disponível em: <http://www.scribd.com/doc/3194328/RIISPOA>. Acesso em:10 set. 2010. 
CERQUEIRA, M. M. O. P. et al. Características microbiológicas de leite cru e beneficiado em Belo Horizonte - MG. Arquivo Brasileiro de Medicina Veterinária e Zootecnia, v. 46, n. 6, p. 713-721, 1994.

CERDÓTES, L. et al. Produção e composição do leite de vacas de quatro grupos genéticos submetidas a dois manejos alimentares no período de lactação. Revista Brasileira de Zootecnia, v. 33, n. 3, p. 610-622, 2004.

CHENETTE, C. G.; FRAHM, R. R. Yield and composition of milk from various two-breed cross cows. Journal of Animal Science, v. 52, n. 3, p. 483-492, 1981.

COBUCI, J. A. et al. Curva de lactação na raça Guzerá. Revista Brasileira de Zootecnia, v. 29, n. 5, p. 1332-1339, 2000.

CRUZ, G. M.; ALENCAR, M. M.; TULIO, R. R. Produção e composição do leite de vacas das raças Canchim e Nelore. Revista da Sociedade Brasileira de Zootecnia, v. 26, n. 5, p. 887-893, 1997.

FAGAN, E. P. et al. Avaliação de padrões físico-químicos e microbiológicos do leite em diferentes fases de lactação nas estações do ano em granjas leiteiras no estado do Paraná - Brasil. Semina: Ciências Agrárias, v. 29, n. 3, p. 651-660, 2008.

GONZALEZ, H. L. et al. Avaliação da qualidade do leite na bacia leiteira de pelotas, RS. Efeito dos meses do ano. Revista Brasileira de Zootecnia, v. 33, n. 6, p. 1531-1543, 2004.

PADILHA, M. R. F.; FERNANDES, Z. de F. Avaliação higiênico-sanitária do leite “C” comercializado no Recife - PE. Higiene Alimentar, v. 13, n. 61, p. 105-109, 1999.

PRASAD, H.; SENGAR, O. P. S. Milk yield and composition of the Barbari gota breed and its cross with Jamunapari, Beetal and Black Bengal. Small Ruminant Research, v. 45, p. 79-83, 2002.

RAIMONDO, R. F. S. et al. Avaliação do pH e da eletrocondutividade do leite de bovinos da raça Jersey durante o primeiro mês de lactação. Semina: Ciências Agrárias, v. 30, n. 2, p. 447-456, 2009.

RAPACCI, M. Tecnologia de leite. Curitiba: PUCPR/Departamento de Engenharia de Alimentos, 2000. Apostila digitada.

RESTLE, J.; PACHECO, P. S.; MOLETTA, J. L. Grupo genético e nível nutricional pós-parto na produção e composição do leite de vacas de corte. Revista Brasileira de Zootecnia, v. 32, n. 3, p. 585-597, 2003.

SANTOS, E. C.; XAVIER, A. T. V.; PASSOS, L. A. S. Aparente deflexão sazonal de alguns constituintes do leite no início da primavera. Revista do Instituto de Laticínios Cândido Tostes, v. 36, n. 215, p. 9-15, 1981.

SILVA, F. de A. S.; AZEVEDO, C. A. V. de. Principal components analysis in the software Assistat-Statistical Attendance. In: WORLD CONGRESS ON COMPUTERS IN AGRICULTURE, 7., 2009, Reno. Proceedings... Reno: American Society of Agricultural and Biological Engineers, 2009.

SANT'ANA, V. A. C. Proteinograma do leite de vacas: padrões e variabilidade. 2004. 161 f. Dissertação (Mestrado em Clínica Veterinária) - Faculdade de Medicina Veterinária e Zootecnia, Universidade de São Paulo, São Paulo, 2004.

SOLER, C. P. A.; DE PAZ, M.; NUÑEZ, M. The microbiological quality of milk produced in the Balearic Islands. International Dairy Journal, v. 5, p. 69-74, 1995.

SOUZA, M. R. et al. Pasteurização do leite. Caderno Técnico da Escola de Veterinária UFMG, n. 13, p. 85-93, 1995. VENTURINI, K. S.; SARCINELLI, M. F.; SILVA, L. C. da. Características do leite. Vitória: Universidade Federal do Espírito Santo/Pró-Reitoria de Extensão, Programa Institucional de Extensão, 2007. (Boletim Técnico- PIE-UFES: 01007).

Recebido: $14 / 08 / 2010$

Received: 08/14/2010

Aprovado: $21 / 09 / 2010$

Approved: 09/21/2010

Rev. Acad., Ciênc. Agrár. Ambient., Curitiba, v. 8, n. 4, p. 409-415, out./dez. 2010 